\title{
Perancangan Sistem Kendali Temperature Suhu dan Level Oil Pada Prototype Transformator Tenaga
}

\section{Design of Control System Temperature and Oil Level on The Power Transformator Prototype}

\author{
Fajar Ramadhan Pratama ${ }^{1 *}$, Peby Wahyu Purnawan ${ }^{2}$ \\ ${ }^{1,2}$ Teknik Elektro Universitas Budi Luhur \\ Jl. Ciledug Raya, Petukangan Utara, Jakarta Sealatan, 12260. \\ Fajarpratama887@ gmail.com ${ }^{1 *}$, pebywahyupurnawan@budiluhur.ac.id ${ }^{2}$
}

\begin{abstract}
Abstrak - Dalam beberapa transformator yang terdapat di unit gardu induk PLN sering terjadi peningkatan temperatur suhu oil secara drastis dikarenakan kurang efektif dalam metode sistem pendinginan. Selain itu sering terjadi kebocoran kecil pada penutup atau sambungan tangki transformator yang mengakibatkan menurunnya level oil pada transformator yang dapat membuat kerusakan pada transformator tersebut. Makalah ini membahas rancangan sebuah prototype sistem kendali suhu oil (dimana oil di ganti dengan air keran) yang dapat mengendalikan temperatur suhu oil pada tangki transformator agar tidak terjadi overheat dengan mengatur kecepatan putaran kipas dan kendali level oil yang dapat menjaga level oil dalam kondisi selalu full. Sistem yang dirancang terdiri dari mikrokontroler Arduino Nano, sensor DS18B20, sensor DHT22, kipas pendingin, sensor level 1, sensor level 2, pompa pengisian, LCD (Liquid Cyrstal Display). Dalam sistem kendali suhu oil dengan metode fuzzy terdapat 2 inputan yaitu suhu oil dan suhu udara yang difuzzyfikasi menjadi 5 membership function dengan output nilai kecepatan untuk mengatur putaran kipas. Metode Defuzzyfikasi yang digunakan adalah WAA (Weighted Average Area). Hasil yang didapatkan suhu oil transformator stabil pada suhu $40^{\circ} \mathrm{C}-41^{\circ} \mathrm{C}$ sehingga peralatan transformator tidak akan cepat rusak dan pembebanan akan lebih efektif. Sementara itu, hasil kendali level oil selalu dalam kondisi Full sehingga transformator tidak akan padam dikarenakan level oil kurang.
\end{abstract}

Kata kunci: Transformator, Suhu Oil, Level Oil, Kontrol fuzzy, Kontrol On-Off.

\begin{abstract}
Sometimes, the transformers in the PLN Substation Unit has common problem such as the increases of oil temperature since ineffective method in cooling system. As well as frequent small leaks in the cover or connection of the transformer tank resulting in a decrease in the oil level in the transformer which can cause damage to the transformer. This paper describe a design of system prototype for an oil temperature control system which can control the temperature of the oil temperature in the transformer tank so that there is no overheating. The controlling is by adjusting the fan speed and control the oil level which can keep the oil level in full condition. The system designed consists of an Arduino Nano microcontroller, DS18B20 sensor, DHT22 sensor, cooling fan, level 1 sensor, level 2 sensor, filling pump, LCD (Liquid Cyrstal Display). We used a fuzzy logic method in oil temperature control. There are 2 inputs, namely the oil temperature and air temperature which are fuzzyfied into 5 membership functions with the output speed values to regulate fan rotation. We used Weighted Average Area (WAA) for defuzzyfication process. Based on the results, we obtained that the transformer oil temperature is stable at a temperature
\end{abstract}

TELKA, Vol.6, No.2, November 2020, pp. 85 92

ISSN (e): 2540-9123

ISSN (p): 2502-1982 
of $40^{\circ} \mathrm{C}-41^{\circ} \mathrm{C}$ so that the transformer equipment will not be damaged quickly and the loading will be more effective. Furthermore, the results of the oil level control are always in full condition so that the transformer will not go out because the oil level is not enough.

Keywords: Transformator, Oil Temperature, Oil Level, Fuzzy Control, On-Off Control.

\section{Pendahuluan}

Transformator tenaga mempunyai arus nominal, arus nominal adalah arus beban maksimal yang bisa ditampung oleh transformator tenaga tersebut. Operasi transformator tenaga dengan beban yang tinggi akan mengakibatkan suhu oil pada transformator meningkat. Di beberapa transformator yang sudah lama beroperasi sering terjadi peningkatan suhu oil yang drastis bersamaan dengan meningkatnya arus beban pada transformator sehingga pembebanan pada transformator tenaga tersebut tidak bisa optimal dan maksimal. Supaya kinerja sistem pendingin mempunyai kinerja yang bagus, maka harus dilakukan optimalisasi kendali suhu pada sistem pendingin tersebut.

Selain suhu oil transformator, hal lain yang tidak kalah pentingnya adalah level oil transformator sering terjadinya kebocoran pada karet penutup transformator ataupun pada sambungan mekanik transformator dapat menyebabkan berkurangnya level oil pada tangki transformator yang jika tidak terkontrol dapat memutuskan pemutus tenaga yang menyebabkan padamnya transformator tersebut. Sedangkan dalam satu unit PT.PLN (persero) hanya memiliki satu alat penambah minyak transformator yang dipakai juga untuk di gardu induk lain dengan dioperasikan secara manual sehingga tidak efektif dalam penanganan gangguan transformator.

Dengan dirancangnya sebuah alat kendali suhu oil dan level oil pada transformator tenaga ini diharapkan sistem dalam pembebanan dapat beroperasi secara optima 1 tanpa ada hambatan tingginya temperatur suhu oil dan juga kondisi level oil pada transformator dapat selalu pada kondisi yang aman.

Pada jurnal penelitian $\mathrm{R}$ bangun dan Permukaan didapatkan referensi untuk mengontrol ketinggian level air menggunakan floating system [1]. Pada jurnal penelitian A Alawiyah dan A rafi membandingkan cara mengontrol ketinggian level air menggunakan sensor ultrasonik serta membandingkan dan mengukur tingkat error [2]. Pada penelitian E Wiji dan Kridalaksana membahas pembuatan alat kontrol suhu dan kelembapan pada kandang ayam, sensor suhu yang dipakai DHT11, DHT 11 mendeteksi suhu maupun kelembapan dengan baik, alat ini dilengkapi juga LED buzzer, dan pompa air [3]. Pada jurnal $\mathrm{N}$ febrianto dan Erwin merancang alat pemanas air menggunakan eleman pemanas dengan metode fuzzy logic dengan set point $40^{\circ} \mathrm{C}$ dengan hasil overshoot $0,88^{\circ} \mathrm{C}$ dengan waktu 15 detik [4]. Pada penelitian Syaikhu Mubarak dan Rummi Sirait menilai rancangan alat kalibrasi relay suhu pada transformator untuk dibandingkan dengan sensor suhu PT100 yang lebih relevan dan disesuaikan menggunakan metode PID, error dari penelitian ini didapatkan sebesar 2,5\% [5]. Pada jurnal Yudha Tri merancang alat otomatisasi pengisian minyak pada kabel sktt menggunakan metode PID menggunakan sensor level etape untuk level minyak dan sensor tekanan autonics dengan sensitivitas 0,131 Volt/PSI [6].

Dari beberapa jurnal penelitian yang telah disebutkan penulis mendapatkan referensi bagaimana menentukan sensor yang akan dipakai, metode kontrol yang digunakan, dan perbandingan error yang diinginkan. Penelitian ini menitik beratkan pada pengujian unjuk kerja sistem kendali fuzzy untuk mengendalikan suhu oil dan level oil pada prototipe transformator yaitu dengan cara mengendalikan putaran kipas untuk suhu oil serta mengatur on/off pompa untuk level oil sesuai (rule base) yang digunakan.

\section{Metode Penelitian}

\subsection{Perancangan Perangkat Keras}

Rancangan mekanik dibuat tangki transformator dan tangki cadangan yang berbahan plat besi, tangki transformator dilengkapi radiator yang tersambung dibagian samping depan dimana proses pendinginan suhu berlangsung, sedangkan untuk tangki cadangan dilengkapi pompa 
disampingnya untuk mengisi minyak ke dalam tangki transformator seperti ditunjukkan pada Gambar 1.

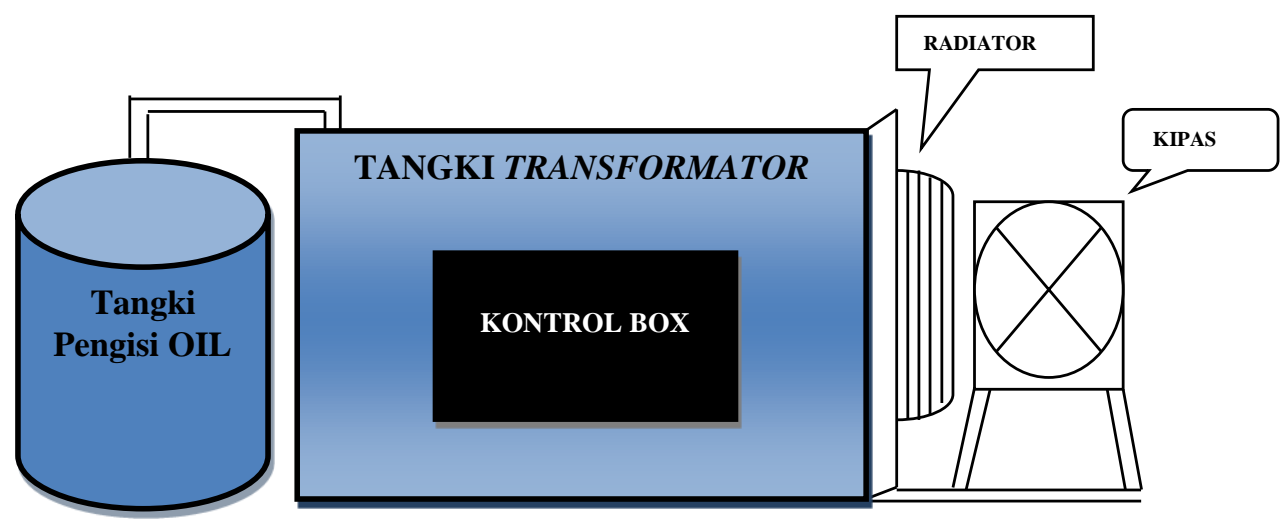

Gambar 1. Rancangan sistem mekanik sistem kendali suhu dan level oil.

\subsection{Rangkaian Sistem Elektronik}

Rangkaian sistem elektronik seluruh pengendalian temperatur suhu oil dan level oil pada transformator tenaga terdiri dari Catu Daya 12V, Arduino Nano, Sensor DS18B20, Sensor DHT 22, sensor level pelampung, driver motor, relay 4 channel, pompa pengisi level oil, Pompa Sirkulasi, Kipas DC Universal, dan Heater.

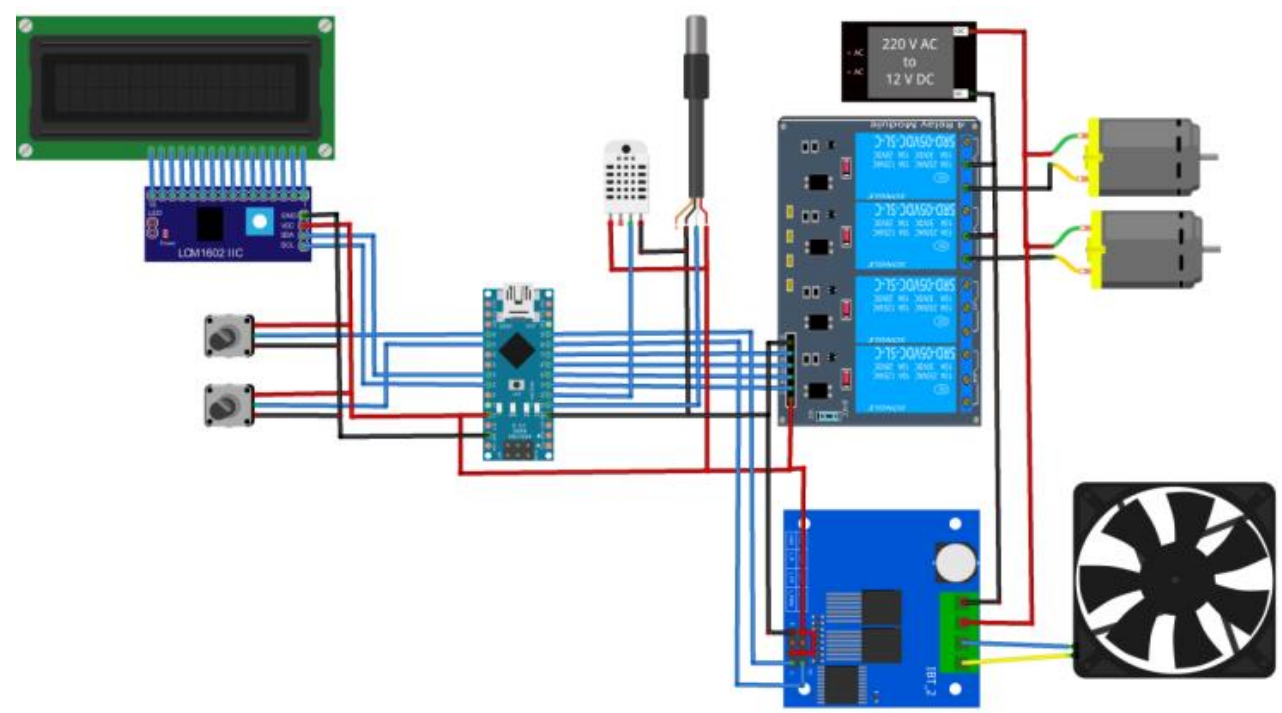

Gambar 2. Rangkaian elektronik keseluruhan.

\subsection{Perancangan Perangkat Lunak}

Dalam tahap ini dijelaskan rancangan perangkat lunak (software) berupa algoritma program pengendalian yang akan ditanamkan pada papan kontroler Arduino Nano. Algoritma program terdiri dari algoritma kontrol $O N-O F F$ dan algoritma pengendali logika fuzzy, logika fuzzy. 

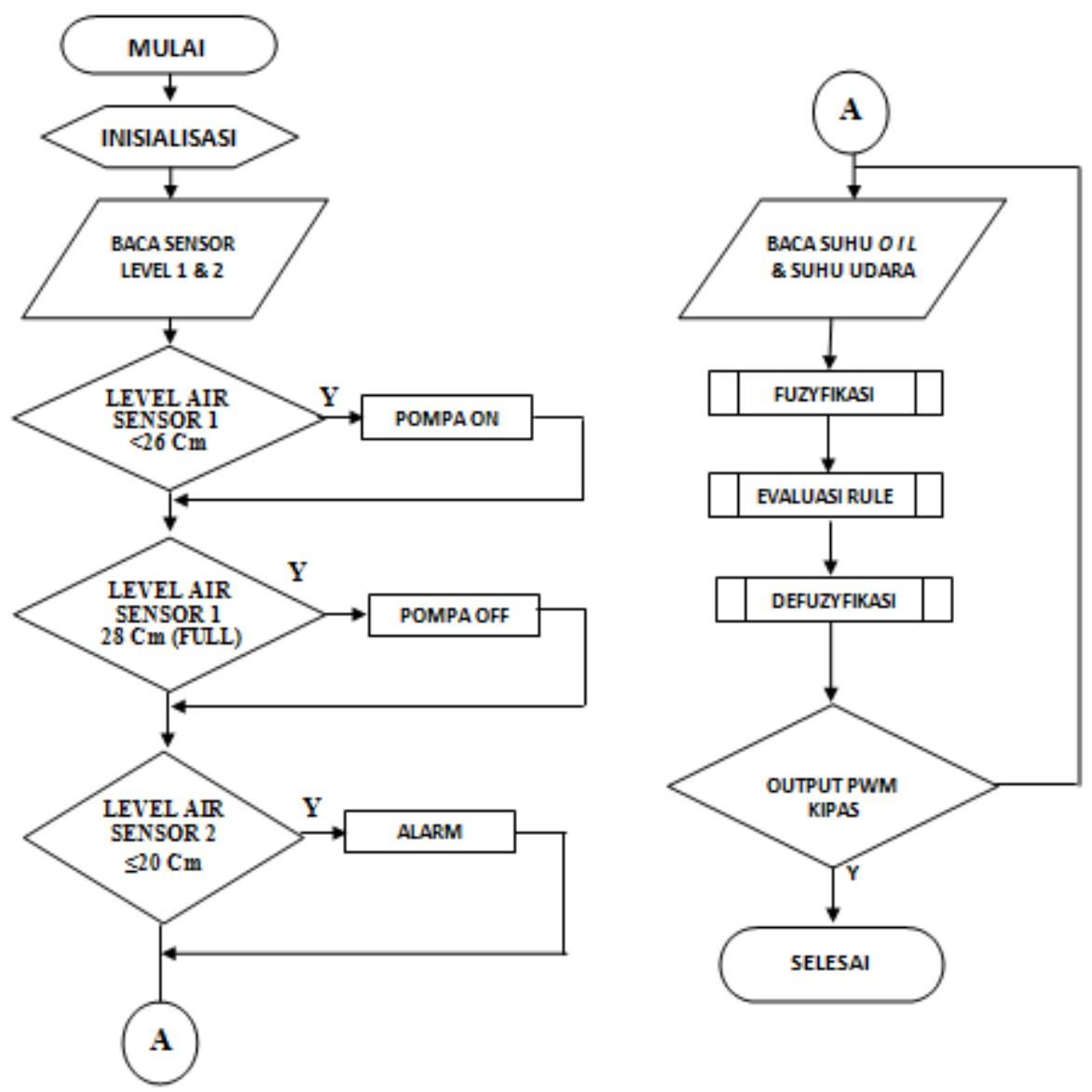

Gambar 3. Diagram alir program kendali temperatur suhu oil dan kendali level oil.

Melalui diagram alir program kendali suhu oil dan level oil dapat dijelaskan sebagai berikut :

1. Program diawali dengan start, selanjutnya program akan melakukan proses inisialisasi.

2. Program akan membaca level air tangki transformator (level 1) dan level air tangki cadangan (level 2) sebagai masukkan algoritma kontrol on-off, selanjutnya apabila level air pada tangki sensor $1 \leq 26 \mathrm{~cm}$ maka pompa pengisi oil akan diaktifkan.

3. Selanjutnya apabila level air sudah mencapai posisi full kettinggian level air pada tangki sensor 1 setinggi $28 \mathrm{~cm}$, maka pompa pengisian akan berhenti (off).

4. Dan apabila ketinggian air sensor level 2 (tangki cadangan) $\leq 20 \mathrm{Cm}$ posisi pelampung di bawah (low) maka akan membunyikan alarm.

5. LCD dan PC akan menampilkan data hasil pembacaan kettinggian air pada tangki sensor level 1 \& 2 secara berkala.

6. Selanjutnya untuk kendali suhu oil program akan membaca temperatur suhu oil sebagai masukkan algoritma fuzzy.

7. Kemudian program akan membaca nilai inputan suhu oil dan suhu udara yang masuk, untuk diolah dengan menggunakan kendali fuzzy logic.

8. Proses fuzzy logic meliputi proses fuzzifikasi, evaluasi rule, defuzzifikasi.

9. Ketika syarat terpenuhi pada rule fuzzy yang telah dibuat maka mikrokontroler akan menghasilkan sinyal keluaran berupa sinyal kendali (sinyal PWM) yang dihubungkan pada driver kipas untuk mengatur kecepatan putaran kipas.

10. Selanjutnya LCD akan menampilkan data hasil pembacaan sensor suhu DS18B20 maupun sensor DHT22 secara berkala.

11. Selesai. 


\subsubsection{Sub Program Fuzzyfikasi}

Pada sub program logika fuzzy, input yang diolah adalah nilai suhu oil dan suhu udara serta output kecepatan putaran kipas yang dapat digambarkan pada diagram blok pengendalian fuzzy seperti Gambar 4.

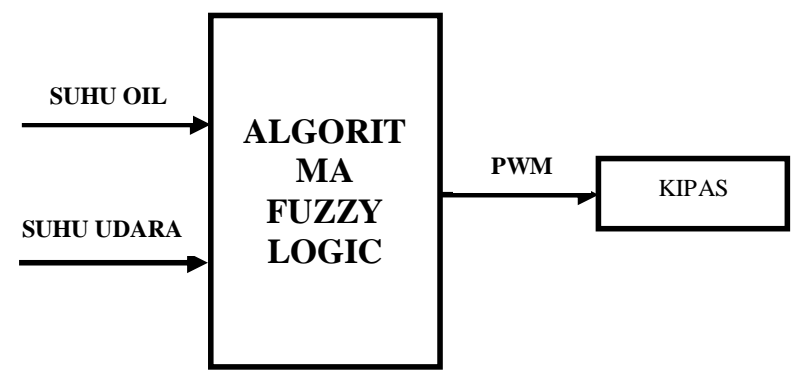

Gambar 4 Diagram blok logika Fuzzy.

Pemetaan input dan output fuzzy yang masing-masing dibagi menjadi 5 fungsi keanggotaan (membership fuction). Range dan Fungsi keanggotaan suhu oil memiliki lima label yaitu Dingin $\left(25^{\circ} \mathrm{C}-30^{\circ} \mathrm{C}\right)$, Normal $\left(28^{\circ} \mathrm{C}-35^{\circ} \mathrm{C}\right)$, Hangat $\left(33^{\circ} \mathrm{C}-40^{\circ} \mathrm{C}\right)$, Panas $\left(38^{\circ} \mathrm{C}-45^{\circ} \mathrm{C}\right)$, dan Sangat panas $\left(43^{\circ} \mathrm{C}-50^{\circ} \mathrm{C}\right)$. Sementara suhu udara masing-masing memiliki lima lebel yaitu Dingin $\left(15^{\circ} \mathrm{C}-20^{\circ} \mathrm{C}\right)$, Sejuk $\left(18^{\circ} \mathrm{C}-25^{\circ} \mathrm{C}\right)$, Normal $\left(23^{\circ} \mathrm{C}-30^{\circ} \mathrm{C}\right)$, Hangat $\left(28^{\circ} \mathrm{C}-35^{\circ} \mathrm{C}\right)$, dan Panas $\left(33^{\circ} \mathrm{C}-40^{\circ} \mathrm{C}\right)$.

Fungsi keanggotaan untuk output juga sangat penting dibuat dalam menentukan rule dan juga defuzifikasi. Range output terdapat 5 fungsi keanggotaan yaitu, Very slow $(0-499 \mathrm{rpm})$, Slow (500 - 999 rpm), Medium (1000 - 1499 rpm), Fast (1500 - 1999 rpm), dan Very Fast (2000 $-2499 \mathrm{rpm})$.

\subsubsection{Sub Program Evaluasi Rule}

Setelah melakukan pemetaan input fuzzy, langkah selanjutnya adalah membuat aturan aturan untuk proses evaluasi rule dengan menggunakan operasi AND [7]. Masukan dan keluaran fuzzy menggunakan 5 fungsi keanggotaan, sehingga terdapat rule sebanyak 25 rule. Berikut adalah Tabel evaluasi rule (Fuzzy Associatte Memory) yang ditunjukan pada Tabel 1.

Tabel 1 Tabel Evaluasi Rule Kendali Suhu Oil

\begin{tabular}{|c|c|c|c|c|c|}
\hline$\widetilde{\text { Udara }}$ Oil & Dingin & Normal & Hangat & Panas & S.Panas \\
\hline Dingin & Vslow & Vslow & Med & Fast & Fast \\
\hline Sejuk & Vslow & Slow & Med & Fast & VFast \\
\hline Normal & Slow & Slow & Med & Fast & Vfast \\
\hline Hangat & Slow & Med & Fast & Vfast & Vfast \\
\hline Panas & Med & Fast & Vfast & Vfast & Vfast \\
\hline
\end{tabular}

\subsubsection{Sub Program Defuzzyfikassi}

Setelah rule ditentukan, maka langkah terakhir yaitu defuzzifikasi dapat dilakukan. Metode yang digunakan adalah dengan menggunakan metode Weighted Average Area. Output fuzzy berupa nilai PWM untuk masukan sebagai kecepatan putaran kipas.

\section{Hasil dan Pembahasan}

\subsection{Pengujian Rangkaian Sistem Keseluruhan}

Tujuan pengujian rangkaian secara keseluruhn ini adalah untuk mengetahui kerja sistem secara keseluruhan dalam melakukan pengendalian suhu oil dan level oil guna mencapai aturan set point yang diharapkan. Sistem kendali suhu oil dengan fuzzy logic controler ini merupakan sistem kendali yang kontinyu dimana sistem akan mengendalikan temperatur suhu oil secara terus menerus sampai stabil. Sedangkan kendali level oil dengan kontrol on-off dimana kendali bekerja 
jika mendapatkan sinyal jika level oil itu dalam posisi perlu dilakukan pengisian oil sehingga pompa On sampai sensor memberikan sinyal bahwa level oil sudah pada batas atas sehinggan pompa Off. Bentuk fisik dari simulator/prototype transformator tenaga dapat dilihat pada Gambar 5 .

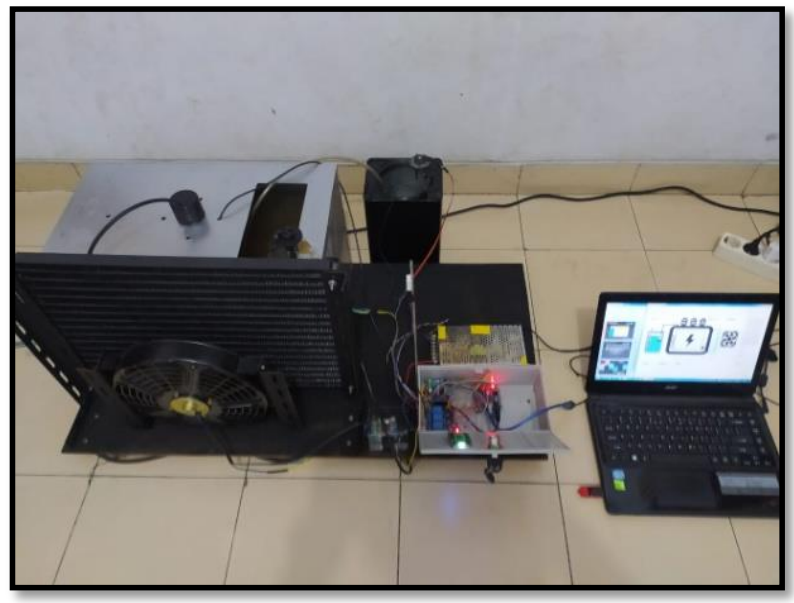

Gambar 5. Alat prototype transformator tenaga kendali suhu dan level oil.

\subsection{Pengujian Kendali Temperatur Suhu Oil}

Pada pengujian kendali temperatur suhu secara keseluruhan didapatkan hasil pengujian seperti pada Gambar 6 pengujian dimulai pada suhu oil $28^{\circ} \mathrm{C}$ dengan acuan suhu air keran, set point dalam jurnal ini adalah $40^{\circ} \mathrm{C}$.

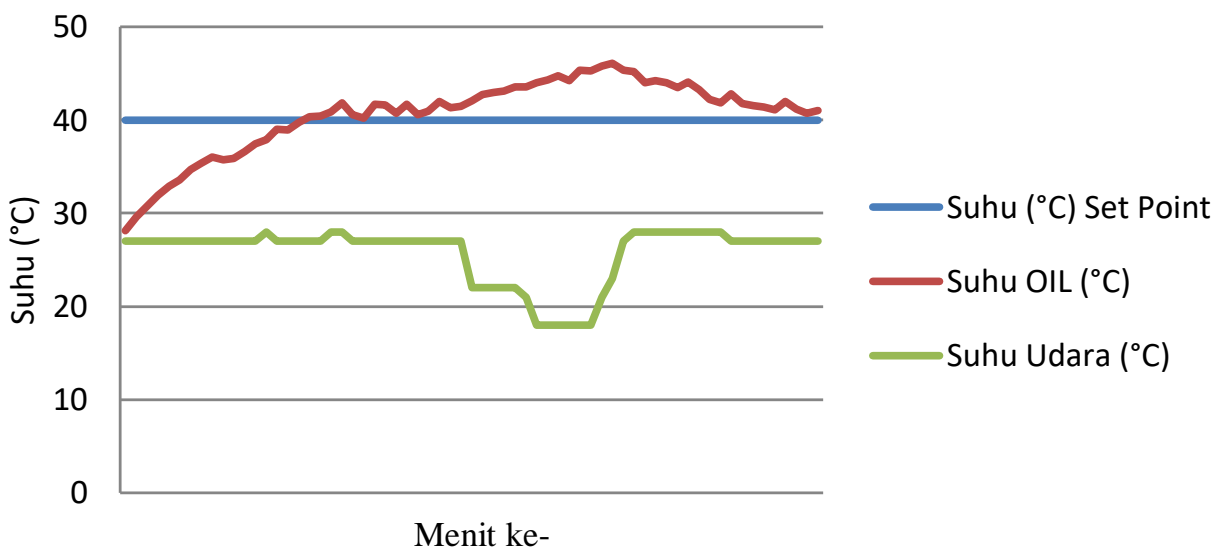

Gambar 6. Grafik pengujian kendali temperatur suhu oil.

Suhu oil meningkat saat kecepatan kipas slow dan medium (sesuai rule). Saat kecepatan kipas Fast suhu oil cenderung stabil di angka $40^{\circ} \mathrm{C}-41^{\circ} \mathrm{C}$, kecepatan kipas Very Fast berfungsi untuk menurunkan suhu oil jika terjadi peningkatan temperatur seperti terlihat dalam tabel 2 Nilai steady state pada pengujian ini adalah 40,61 pada menit 22.

Berdasarkan konsep delay yang menyatakan bahwa delay time adalah ukuran waktu yang menyatakan faktor keterlambatan respon output terhadap nilai set poin, dikukur mulai $\mathrm{t}=0$ sampai respon meraih nilai setengah dari keadaan steady [8], maka delay time diperoleh dengan menetapkan waktu saat $\mathrm{t}=0$ adalah menit ke -01 , waktu saat keadaan $50 \%$ dari keadaan steady menit ke -21 , maka delay time $=22$ menit -1 menit $=20$ menit.

Error Steady State [8] merupakan selisih nilai akhir dengan input (target). Error steady state (Ess) dapat dihitung dengan persamaan:

$$
E s S=S p-P v,
$$


dimana $S p$ adalah Set point, dan $P v$ adalah output rata-rata keadaan steady. Berdasarkan data yang ada, dengan $S p$ sebesar $40^{\circ} \mathrm{C}, P v$ sebesar $40,61^{\circ} \mathrm{C}$ (menit ke-22), maka

$$
\text { Ess }=40-40,61=0,61
$$

Presentasi kesalahan steady state error dapat dihitung dengan:

$$
\% \text { Ess }=\frac{E s s}{S p}-100 \%,
$$

sehingga $\%$ Ess $=0,61 / 40 \times 100 \%=1,52 \%$.

\subsection{Pengujian Keseluruhan Kendali Level Oil}

Sebelum dimulai pengujian keseluruhan dimulai, air dalam tangki transformator tidak di isi dengan full agar saat dimulai pengujian ini diawali dengan pembacaan level oil pada tangki transformator dalam keadaan low sehingga sensor level dapat memberikan sinyal untuk menghidupkan pompa agar mengisi oil dalam tangki.

Hasil pengujian level oil saat pengujian keseluruhan dapat dilihat pada Tabel 3.

Tabel 3. Pengujian keseluruhan level oil.

\begin{tabular}{ccccc}
\hline \multirow{2}{*}{ NO } & \multirow{2}{*}{$\begin{array}{c}\text { Tinggi Air Menggunakan } \\
\text { Penggaris }\end{array}$} & Posisi Pelampung & \multicolumn{2}{c}{ Pompa Pengisian } \\
\cline { 4 - 5 } & $28 \mathrm{Cm}$ & Full & OFF & Pengujian \\
\hline 1 & $26 \mathrm{Cm}$ & Rather Full & ON & OFF \\
2 & $25 \mathrm{Cm}$ & Medium & ON & ON \\
3 & $24 \mathrm{Cm}$ & Rather Low & ON & ON \\
4 & $22 \mathrm{Cm}$ & Low & ON & ON \\
5 & & & \\
\hline
\end{tabular}

Pada Tabel 3 hasil pengujian kendali level oil secara keseluruhan yaitu pompa akan On ketika pembacaan sensor level pada tangki transformator di bawah batas full dan pompa pengisi akan off jika pembacaan sensor level pada tangki transformator dalam keadaan full serta alarm akan berbunyi jika sensor level pada tangki cadangan dalam posisi low. Sistem kendali level oil dalam pengujian ini dapat disimpulkan berjalan dengan baik dan sesuai aturan set point yang dibuat.

\section{Kesimpulan}

Berdasarkan hasil pengujian dan pembahasan mengenai perancangan prototype sistem kendali temperatur suhu dan level oil pada transformator tenaga. Diambil kesimpulan bahwa untuk mengendalikan temperatur suhu oil supaya stabil sesuai set point dapat dilakukan dengan mengatur kecepatan putaran kipas pada tingkat Fast dengan suhu udara normal dan hasil yang diperoleh respon sistem dengan delay time 20 menit dan steady state error sebesar 0,61 pada set point $40^{\circ} \mathrm{C}$ dengan persen error steady state sebesar $1,52 \%$. Serta untuk kendali level oil menunjukan sesuai setting, pompa akan mengisi jika level oil di tangki transformator berkurang hingga $\leq 26 \mathrm{~cm}$ dan pompa berhenti pada level oil $28 \mathrm{~cm}$ dalam keadaan full.

\section{Referensi}

[1] R. Bangun, S. Kendali, and L. Permukaan, "Rancang Bangun Sistem Kendali Level Permukaan Air Menggunakan Mikrokontroler Arduino Uno Untuk Pembudidayaan Hidroponik Metode Floating System," Unnes Phys. J., vol. 5, no. 1, pp. 18-22, 2016.

[2] A. Alawiah and A. Rafi Al Tahtawi, Sistem Kendali dan Pemantauan Ketinggian Air pada Tangki Berbasis Sensor Ultrasonik, vol. 1, no. 1. 2017.

[3] E. Wiji, S. Budianto, and A. H. Kridalaksana, "Kelembaban Kandang Ayam Boiler Berbasis Mikrokontroler Atmega328," Pros. Semin. Nas. Ilmu Komput. dan Teknol. Inf., 
vol. 2, no. 2, 2017.

[4] N. Febrianto, E. Susanto, A. S. Wibowo, F. T. Elektro, and U. Telkom, "Rancang Bangun Kontrol Suhu Air Pada Prototipe Pemanas Air Menggunakan Logika Fuzzy," J. IT, vol. 3, no. 3, pp. 4253-4260, 2016.

[5] S Mubarok, Rummi Sirait, "Alat Kalibrasi Relay Suhu Berbasis Mikrokontroler Atmega32", Univ. Budi Luhur, 2014

[6] Yudha Tri G, , "Otomatisasi Sistem Penambahan Minyak Pada Saluran Kabel Tegangan Tinggi Berbasis Mikrokontroler Atmega32", Univ. Budi Luhur, 2016.

[7] S. Wahyono and M. Arief, "Seledri Menggunakan Kontrol Fuzzy Logic", Edu Elektrika Journal, vol. 4, no. 2, pp. 21-26, 2015.

[8] S. Romadhan, B. Setiyono, and Sumardi, "Menggunakan Kontrol Fuzzy Untuk Pengaturan Suhu Cairan Berbasis Atmega16," Transient, vol. 3, no. 4, p. 617, 2014. 